\title{
Quality of life after spinal cord injury: a meta analysis of the effects of disablement components
}

\author{
Marcel Dijkers
}

Manager of Research, Rehabilitation Institute of Michigan, Wayne State University, Detroit, MI 48201, USA

\begin{abstract}
While objective measures of impairment, disability and handicap can serve as outcome measures for the providers of medical and vocational rehabilitation services, for persons with spinal cord injury (SCI) themselves the only relevant measure of quality of life (QOL) is their own judgment as to their well-being. Subjective QOL in persons with SCI has been measured as happiness, psychological well-being, morale and life satisfaction. Various studies have reported inconclusive or contradictory findings, likely due to small sample size, sample composition, measures used, and other methodological issues. A meta analysis was performed to try to resolve these apparent discrepancies.

A total of 22 studies, with an average sample size of 102, was retrieved. Information on the relationship between QOL and impairment, disability, and handicap, if provided, was abstracted. Findings include the following: persons with SCI tend to report lower subjective well-being than non-disabled people; the relationship between impairment and QOL is weak (mean correlation: $-0.05 ; 95 \%$ confidence interval: -0.12 to 0.02 ), and generally not found to be statistically significant; the association between disability and QOL is somewhat stronger (mean $\mathrm{r}$ : -0.21 ; confidence interval: -0.27 to -0.14 ), but not found consistently; the relationship between QOL and (aspects of) handicap is strongest (range for mean $\mathrm{r}$ : -0.17 to -0.48 ), and fairly consistently found.

The number of studies available is too small to make analysis of factors that explain contradictory findings possible. Further use of subjective QOL measures in research on longterm outcomes of SCI is recommended, in order to properly reflect the perspective of the patients/clients themselves.
\end{abstract}

Keywords: quality of life; spinal cord injuries; meta-analysis

\section{Introduction}

Quality of life means many things to many people. Some emphasize material possessions; others focus on the integrity and functioning of the body; some refer to the quantity and quality of interpersonal relations and others again focus on life satisfaction or mental and spiritual well-being. Whatever one's conception, most people will agree that a spinal cord injury (SCI) constitutes a significant challenge to quality of life (QOL).

A spinal injury affects, directly or indirectly, those aspects of life that have been declared by researchers to constitute QOL or at least found to greatly influence people's judgments of QOL: health and personal safety, independence, the ability to earn an income, access to material comforts, the ability to have and raise children, the likelihood of developing a close relationship with a member of the opposite sex, or a

Correspondence: M Dijkers

Parts of this paper were presented at the 1996 annual meeting of the American Spinal Injury Association, Seattle WA, USA close and supportive network of friends. Body image, self-concept and one's understanding of self may be significantly affected, directly or indirectly.

However, as independent living proponents point out, a spinal cord injury does not necessarily diminish QOL. Provided resources are available (foremost, medical rehabilitation, assistance with coping and adjustment, and a supportive social network) and provided that social reactions, public policies and environmental barriers do not prevent the person from pursuing work, education, leisure, civic duties and other activities, the quality of the life of a person with SCI can be very similar to that of the average non-disabled person. It even may be better than before injury, or than experienced by non-disabled peers. ${ }^{1}$

We have limited information on what are the determinants of QOL for persons with SCI, overall and in various subgroups. We know even less how subjective QOL changes over time after injury, as the person and his social circle adjust (or fail to adjust) to the new realities in their lives. More research in this area is needed. 
The measurement of quality of life

Two approaches have been used to investigate QOL of individuals. ${ }^{2,3}$ The subjective approach (also designated as the evaluative or internal determinants method), exemplified by the work of Andrews and Withey ${ }^{4}$ and Campbell et $a l^{5}$ defines QOL as the congruence between aspirations and accomplishments, as perceived by the person involved. Judgments on congruence can be either more cognitive - the approach taken by the life satisfaction proponents (eg Cantril ${ }^{6}$ and Zhan ${ }^{7}$ ), or predominantly emotional - the approach of those who focus on happiness or positive and negative affect (eg Bradburn $^{8}$ ). The objective approach defines QOL as the sum total of a person's scores on characteristics that can be objectively determined. The components of QOL are such simple things as income level, the number of television sets in the home, and the desirability of the neighborhood in which it is located. All are characteristics that are (supposedly) valued with a high level of consensus by members of a society - eg to be well-educated is better than to be poorly educated; having few symptoms of a chronic disorder is better than having many symptoms.

Health-related QOL (HRQOL) refers to those components of overall (objective) QOL that center upon or are directly and indirectly affected by health, disease, disorder and injury: signs, symptoms, treatment side effects, physical, cognitive, emotional and social functioning, etc. ${ }^{3}$ It commonly is used as a measure of health care outcome, and as such overlaps with the concept of health status. There is quite some variety in the nature of the characteristics included in various HRQOL indexes and batteries used in the published literature - functional status, fatigue, pain, social and physical activities, bed or home restriction days, neuropsychological function, etc.

\section{Quality of life after spinal cord injury}

Over the years, a number of studies have investigated components of life quality (as defined in the objective QOL tradition) for persons with SCI. For instance, there are many publications on health status, impairment and disability levels after injury. Studies using the concept of handicap are increasingly being published (eg Whiteneck et $a l^{9}$ ), and there is an extensive older research literature on each of the major constituent components of handicap, eg independent living, marital status, education and employment status, and to a lesser degree on avocational pursuits (see Dijkers et $\left.a l^{10}\right)$. In the objective tradition of QOL research, these are all commonly considered major components of QOL. Some studies have actually used that term (eg DeVivo and Richards ${ }^{11}$; Quiel $^{12}$ ).

An even more extensive literature exists on the psychological and emotional sequelae of spinal cord injury, studied under such labels as coping and adjustment, depression, disability acceptance, and control. $^{13-19}$ The self-reports most of these studies use reflect subjective QOL at least to some degree.
Studies utilizing subjective QOL measures have become more common only during the last 10 years. Crewe $^{20}$ was the first one to systematically study QOL (defined as life satisfaction) in persons with SCI, using a method proposed by Flanagan. ${ }^{21}$ She found that her SCI subjects reported less satisfaction than the nondisabled persons in Flanagan's national study, especially in the domains of sexual relations with spouse, employment (work) and financial (material) well-being, but also in the domains of health and social relationships. This finding was replicated in a number of studies; $;^{22-27}$ only two studies involving (older) veterans report equal or better QOL than the comparison groups involved. ${ }^{28,29}$

Most research has not compared the subjective QOL of persons with SCI with that of non-disabled peers, but has focused on sources of happiness and satisfaction in persons with a spinal injury. Family relationships, living arrangements, social life and passive recreation tend to be domains with which satisfaction is high, while low satisfaction ratings are common for finances, sexual life, and employment. ${ }^{20,27,30,31}$

There is less consensus with respect to other findings. In a recent review, Fuhrer ${ }^{32}$ summarized findings of 19 studies (mostly published since 1990) of the relationship between subjective well-being (satisfaction, morale, happiness, etc) and the three components of disablement: impairment, disability and handicap. His results may be summarized as follows:

Relationship with subjective QOL

\begin{tabular}{lccc}
\hline & $\begin{array}{c}\text { None } \\
\text { (zero) }\end{array}$ & $\begin{array}{c}\text { Negative, } \\
\text { not sign. }\end{array}$ & $\begin{array}{c}\text { Negative, } \\
\text { sign. }\end{array}$ \\
\hline Impairment & 13 & 1 & 1 \\
Disability & 4 & 1 & 2 \\
Handicap & & & \\
$\quad$ occup. status & 2 & & 6 \\
$\quad$ social activity & 1 & & 3 \\
mobility & & & 3 \\
\hline
\end{tabular}

It is possible that the lack of a statistically significant relationship between disablement components and well-being reported by so many of these studies was due to a small sample size. Most investigations did not have sufficient power to demonstrate the existence of even a moderately strong relationship. The discrepant findings may also be due to other methodological weaknesses, the varying nature of the samples employed in the studies (in terms of age, time since injury, gender, etc), or the range of instruments used to measure subjective QOL. Fuhrer ${ }^{32}$ was limited to concluding that QOL appears to be little, if at all, related to impairment, inconsistently to disability, and commonly to various aspects of handicap. The relative strength of the relationships, or the circumstances under which disability affects QOL, could not be addressed in his qualitative review. 
Meta analysis is a method of summarizing the results of existing studies in a particular area quantitatively rather than qualitatively. It statistically pools the results of multiple independent studies, using subgroups of studies (based on nature of sample, research design, etc) as necessary. Problems of small sample size, research design differences and varying nature of samples can be addressed by meta analysis. The purpose of this paper is to describe quantitatively the relationship of subjective QOL with three aspects of disablement; impairment, disability and handicap.

\section{Methods}

Medline, Excerpta Medica, and ClinPSYC searches were used to identify relevant papers. Key words used were spinal cord injury, and life satisfaction, wellbeing, and quality of life. This was supplemented by querying experts, searching the investigator's files, and review of references provided in the studies found. The following criteria were used in selection:

- a subjective QOL measure was used, either a global single item, or an index that combined scores on a broad battery of items. This excluded studies that considered solely eg sexual satisfaction (eg Siösteen et $\left.a l^{33}\right)$.

- empirical data were reported in such a way that at least one effect size measure of the relationship between QOL and disablement could be calculated, for a sample containing only spinal cord injured individuals. This excluded studies that reported on mixed disability samples, eg Stensman ${ }^{34}$ and
Chwalisz et $a l^{35}$, or provided only qualitative findings (eg Dew et $a l^{25}$ ).

A total of 29 publications describing 19 samples was identified (see Table 1). The average sample size was 102 persons, and for the average sample four useful effect sizes could be abstracted or calculated. No evaluation of the quality of research reports was performed. Abstracting of all information was done independently by two persons, using a customdesigned form. The following information was abstracted (if available): bibliographic information; size of sample; distribution by gender and neurological category; mean for current age, age at injury, time since injury, education at injury and current education; impairment, disability and handicap measures reported, and their relationship with QOL; identity of QOL measure(s) used. For those studies that offered a comparison of QOL between persons with SCI and non-disabled persons, QOL information for both groups was abstracted. Disagreements in abstracting were solved by discussion.

In order to maximize the number of effect sizes available for analysis, some estimates were used. For instance, if a report contained means for two groups, but no standard deviations, the standard deviation reported in a different study for the same QOL measure was substituted. All effect sizes and other relevant information was entered into computer files for further processing. The Pearson correlation coefficient was selected as the standard effect size indicator (except for comparisons of persons with SCI and non-disabled groups), and all other effect sizes

Table 1 Demographic and injury information on the samples included in the analysis

\begin{tabular}{|c|c|c|c|c|c|c|c|c|c|c|c|c|c|c|c|}
\hline \multicolumn{2}{|c|}{$\begin{array}{l}\text { Sample \# and } \\
\text { references }\end{array}$} & \multirow{2}{*}{$\begin{array}{c}\begin{array}{c}\text { Sample } \\
\text { size }\end{array} \\
42\end{array}$} & \multicolumn{2}{|c|}{$\begin{array}{l}\text { Gender } \\
\% F \% M\end{array}$} & \multicolumn{2}{|c|}{$\begin{array}{l}\text { Current age } \\
\text { Mean SD }\end{array}$} & \multicolumn{2}{|c|}{$\begin{array}{c}\text { Age at } \\
\text { Injury } \\
\text { Mean SD }\end{array}$} & \multicolumn{2}{|c|}{$\begin{array}{l}\text { Years since } \\
\text { Injury } \\
\text { Mean SD }\end{array}$} & \multicolumn{2}{|c|}{$\begin{array}{c}\text { Current } \\
\text { Education } \\
\text { Mean SD }\end{array}$} & \multicolumn{2}{|c|}{$\begin{array}{c}\text { Injury } \\
\text { Level } \\
\% \text { Par \% Tet }\end{array}$} & $\begin{array}{c}\text { Measure }(s) \\
\text { of } Q O L\end{array}$ \\
\hline $1^{\mathrm{a}}$ & 36 & & 33 & 64 & 33.1 & - & 21.4 & - & 13.4 & - & 12.8 & - & 0 & 100 & 9 \\
\hline $1^{\mathrm{a}}$ & & 45 & 22 & 75 & 36.6 & - & 27.8 & - & 8.9 & - & 13.9 & - & 0 & 100 & 9 \\
\hline 2 & 37 & 174 & 13 & 87 & - & - & 33.0 & - & - & - & - & - & - & - & 9 \\
\hline 3 & 38 & 100 & 20 & 80 & 33.7 & - & 27.3 & - & 6.9 & - & 12.6 & - & 34 & 66 & 1 \\
\hline 4 & 39 & 91 & 19 & 81 & - & - & 21.6 & - & 9.5 & - & - & - & - & - & 4 \\
\hline 5 & 26 & 60 & 17 & 83 & 36.2 & 7.9 & - & - & 11.9 & 7.2 & - & - & 50 & 50 & 2 \\
\hline 6 & 40 & 43 & 28 & 72 & 47.2 & - & 34.2 & - & 12.1 & - & - & - & - & - & 9 \\
\hline 7 & 18,22 & 100 & 10 & 90 & 56.0 & - & 35.0 & - & - & - & - & - & - & - & 2,7 \\
\hline 8 & 30 & 31 & 39 & 61 & 35.0 & - & - & - & - & - & - & - & - & - & 10 \\
\hline 9 & 19,27 & 140 & 29 & 71 & 37.0 & 11.5 & 26.4 & 11.0 & 10.6 & 7.8 & - & - & - & - & 2 \\
\hline $10^{\mathrm{b}}$ & 23,41 & 98 & 17 & 83 & 33.5 & - & - & - & 2.3 & - & - & - & - & - & 9 \\
\hline 11 & 42 & 70 & 0 & 100 & 55.2 & 7.5 & 25.3 & 7.6 & 29.5 & 8.1 & - & - & 47 & 53 & 5 \\
\hline 12 & 43 & 40 & 0 & 100 & 51.4 & 10.2 & - & - & 22.3 & 12.3 & 12.1 & 2.4 & 50 & 50 & 6 \\
\hline 13 & 44 & 17 & 12 & 88 & - & - & - & - & - & - & - & - & 41 & 59 & 9 \\
\hline 14 & 45 & 128 & 14 & 86 & - & - & - & - & - & - & - & - & 0 & 100 & 9 \\
\hline 15 & 9,46 & 282 & 13 & 87 & 53.2 & - & - & - & - & - & - & - & 65 & 35 & $2,3,7,9$ \\
\hline $16^{\mathrm{c}}$ & $14,31,47-52$ & 449 & 18 & 82 & 35.2 & 13.0 & 25.7 & 12.0 & 9.5 & 6.0 & 13.1 & 3.0 & 45 & 55 & 8 \\
\hline 17 & 53 & 29 & 21 & 79 & 23.0 & - & - & - & - & - & - & - & 38 & 62 & 11 \\
\hline 18 & 54 & 15 & 33 & 67 & 38.1 & - & - & - & - & - & - & - & 27 & 73 & 9,12 \\
\hline
\end{tabular}

${ }^{\mathrm{a}}$ Information on two separate subsamples. ${ }^{\mathrm{b}}$ Information from reference 27 . See text. ${ }^{\mathrm{c}}$ Information from reference 54 . See text. 
(most frequently, $t$-tests) were 'translated' into correlations using standard formulas. ${ }^{55}$

Several publications provided information on the same sample (see reference listing in Table 1). These were compared, and duplicative effect sizes eliminated. Krause and colleagues wrote a series of papers ${ }^{14,31,47-52}$ on data resulting from a partly cross-sectional (cohorts established in 1973 and 1985), partly longitudinal (data collection in 1973, 1985 and 1989) design, with the number of cases dissimilar in most papers due to the subsample considered. After much study, it was decided to treat this as a single study. The two papers by Siösteen et $a l^{23,41}$ also appear to describe the same sample, with the later publication having a larger size. They were also considered one sample.

Most studies reported effect size information for multiple indicators for each of the categories of correlates of QOL (especially handicap), and some used multiple QOL measures. All effect size calculations based on the combined samples were done in two ways: with and without such duplications. This allows estimation of the contribution of studies that report multiple results.

In most social and behavioral research, not all subjects complete all questions or tests; consequently, the actual number of cases $(\mathrm{N})$ for each reported statistical test is smaller than the nominal sample size reported in the 'Methods' section of publications. Most papers do not report the actual $\mathrm{N}$ for each test, and meta-analysis is forced to use the nominal N. This may artificially inflate the cumulative sample size, and make it more likely to find statistical significance. In the current analysis, for most effect sizes abstracted only the nominal $\mathrm{N}$ was available.

For comparisons between persons with SCI and non-disabled persons, a table presenting number of cases, mean, and standard deviation for the two groups is presented, as well as (if available), the results of a $t$-test (as reported by the authors or calculated from their data), and Cohen's d. The latter is defined as $\left(X_{n}-X_{s}\right) / S_{n}$, where $X_{n}$ is the mean for the non-disabled group, $X_{s}$ the mean for the SCI group, and $\mathrm{SD}_{\mathrm{n}}$ the standard deviation for the group that is the basis for comparison, the nonSCI sample.

For each of the other categories of correlates of QOL, a table is presented that contains all information that could be abstracted. The table gives the sample number (Sample \#) (corresponding to the number in Table 1), the specific measure of QOL used (QOL \#), the size of the correlation that was reported (or calculated based on other data provided by the authors) (Corr.) as well as the number of (actual or nominal) cases for that correlation (Cases). The significance level reported by the authors or determined using statistical tables is provided (p), as well as the lower and upper bound of the $95 \%$ confidence interval for the correlation. For those instances where authors did not report the correlation (or equivalent information), the sign of the correlation is reported, if available. This allows one to assess whether non-reported correlations have a trend similar to reported ones. Lastly, an asterisk indicates those reported correlations that were included in the random sample drawn to prevent basing conclusions on multiple reports for the same sample. Figure 1 provides an index of the specific QOL measures used in each study included in the analysis. The separate tables indicate what specific measures of impairment, disability and handicap were used in each case.

At the bottom of the tables are provided the following meta analysis results, for all correlations and for the random sample: (1) the mean correlation (calculated by weighting each reported correlation by the applicable sample size); (2) its confidence interval; (3) the value of $p$ for a statistical test of the hypothesis that the average correlation is not significantly different from 0.00. A test of homogeneity is also provided. If this test results in a $p$-value smaller than 0.05 , it is likely that the correlations summarized are based on substantially different samples (eg US versus Sweden), and/or essentially different QOL measures or predictor measures; it suggests that computing a mean correlation in these instances is akin to calculating the mean of apples and oranges.

\section{Results}

The cases included in the samples selected for this analysis appear to be fairly typical of persons with SCI (Table 1): the majority are males (64 to $100 \%$ ), injured at a young age (mean from 21 to 35 years), and about 10 years post injury. The major exception to the latter are the studies that on purpose selected 'older' cases (samples 9, 13, and 18). The percentage of cases with tetraplegia tends to be over $50 \%$; again, some studies selected such cases exclusively (samples 1, 17).

\section{Impairment}

Comparisons of the QOL of persons with SCI to that of non-disabled persons are summarized in Table 2. In

1 LSS: Life Situation Survey

2 LSIA-A: Life Satisfaction Index-A

3 Quality of Life and Individual Needs Questionnaire

4 Life 3 Measure

5 Quality of Life Index (Michalos)

6 Quality of Life Index (Padilla and Grant)

7 IPWB: Index of Psychological Well Being

8 LSQ: Life Situation Questionnaire, Factor 1

9 any single-item life satisfaction measure

10 LSES: Life Satisfaction of the Elderly Scale

11 any single-item happiness item

12 Cantril ladder

Figure 1 Index of QOL measures used in various studies of the relationship of QOL with disablement 
all instances but two, the QOL of the SCI sample is lower than that of the comparison group selected. The two exceptions are comparisons of the same SCI sample with back pain patients $(N=22)$ and prisoners $(N=44)$, respectively. ${ }^{38}$ Because of the extensive overlap within the SCI samples and the non-SCI samples, no cross-samples effect size was calculated.

Studies that considered the relationship of QOL to impairment level (Table 3) are based most frequently on a comparison between persons with paraplegia and those with tetraplegia, but ASIA motor scores, ${ }^{56}$ differences between persons with complete and incomplete injuries, and differences between ventilator-dependent and non-dependent tetraplegic individuals are also included. This combination may explain the heterogeneity of results, although it is not exorbitant. The average correlation of -0.05 indicates that degree of impairment by itself has a very minor effect on QOL. In fact, the correlation is not significantly different from 0.00 , absence of a relationship. Figure 2 provides a graphic presentation of all mean effect sizes calculated, and their confidence intervals.

\section{Disability}

Seven studies reported on the association between disability and QOL, which generally was found to be negative (the higher the disability level, the lower the QOL reported), and was weak to moderately strong

Table 2 Results for the comparison of persons with SCI with non-disabled persons

\begin{tabular}{|c|c|c|c|c|c|c|c|c|c|c|}
\hline \multirow{2}{*}{$\begin{array}{l}\text { Sample } \\
\#\end{array}$} & \multirow{2}{*}{$\begin{array}{c}Q O L \\
\#^{I}\end{array}$} & \multicolumn{3}{|c|}{ SCI group } & \multicolumn{3}{|c|}{ Non-SCI group } & \multicolumn{2}{|c|}{$\mathrm{t}$-test } & \multirow{2}{*}{$\begin{array}{c}\text { Cohen's } \\
d\end{array}$} \\
\hline & & Cases & Mean & $S D^{2}$ & Cases & Mean & $S D^{2}$ & $\mathrm{t}$ & $\mathrm{p}$ & \\
\hline 1 & 9 & 45 & 4.09 & 1.73 & 259 & 5.36 & 1.18 & -6.14 & $<0.001$ & -0.99 \\
\hline 1 & 9 & 42 & 4.39 & 1.75 & 259 & 5.36 & 1.18 & -4.56 & $<0.001$ & -0.76 \\
\hline 3 & 1 & 100 & 89.5 & 15.0 & 50 & 107.0 & 11.2 & -7.25 & $<0.001$ & -1.26 \\
\hline 3 & 1 & 100 & 89.5 & 15.0 & 22 & 81.1 & 20.9 & - & - & 0.55 \\
\hline 3 & 1 & 100 & 89.5 & 15.0 & 44 & 74.0 & 14.9 & 5.68 & $<0.001$ & 1.03 \\
\hline 7 & 2 & 100 & 10.8 & $4.3 \mathrm{E}$ & 4254 & 13.2 & $4.3 \mathrm{E}$ & -5.52 & $<0.001$ & -0.56 \\
\hline 7 & 7 & 100 & 2.96 & 1.28 & 6928 & 3.23 & 1.51 & -1.78 & $>0.05$ & -0.18 \\
\hline 9 & 2 & 140 & 8.8 & 4.3 & 4254 & 13.2 & $4.3 \mathrm{E}$ & -11.91 & $<0.001$ & -1.02 \\
\hline 10 & 9 & 96 & 58.6 & $40 \mathrm{E}$ & 83 & 16 & - & - & - & -0.61 \\
\hline 17 & 11 & 29 & 2.96 & - & 22 & 3.82 & - & -2.68 & $<0.01$ & - \\
\hline 18 & 12 & 15 & 5.86 & 1.7 & 12 & 6.50 & 1.31 & -1.03 & $>0.05$ & -0.40 \\
\hline 18 & 9 & 15 & - & - & 12 & - & - & - & $>0.05$ & - \\
\hline
\end{tabular}

${ }^{1}$ See Index of QOL measures in Figure 1. ${ }^{2}$ Standard deviations denoted by 'E' are estimates

Table 3 Results for association of QOL with impairment

\begin{tabular}{|c|c|c|c|c|c|c|c|c|c|}
\hline Sample & $\underset{\#^{1}}{Q O L}$ & $\underset{\#^{2}}{\operatorname{Imp}}$ & Cases & Corr. & $\begin{array}{l}\text { Confidence } \\
\text { Low }\end{array}$ & $\begin{array}{r}\text { Interval } \\
\text { High }\end{array}$ & $\mathrm{p}$ & $\begin{array}{l}\text { Undupl. } \\
\text { sample }\end{array}$ & $\begin{array}{l}\text { Homo- } \\
\text { geneity }\end{array}$ \\
\hline 4 & 4 & 2 & 91 & $?$ & - & - & $>0.05$ & & \\
\hline 7 & 2 & 3 & 100 & neg & - & - & $>0.05$ & & \\
\hline 11 & 5 & 3 & 70 & $?$ & - & - & $>0.10$ & & \\
\hline 15 & 7 & 2 & 282 & $?$ & - & - & $>0.05$ & & \\
\hline 16 & 8 & 3 & 390 & $?$ & - & - & $<0.01$ & & \\
\hline 12 & 6 & 2 & 40 & -0.28 & -0.54 & 0.03 & $<0.05$ & $*$ & \\
\hline 3 & 1 & 2 & 100 & -0.32 & -0.49 & -0.13 & $<0.01$ & $*$ & \\
\hline 13 & 9 & 2 & 17 & 0.02 & -0.47 & 0.50 & $>0.05$ & $*$ & \\
\hline 5 & 2 & 3 & 60 & -0.19 & -0.42 & 0.07 & $>0.05$ & $*$ & \\
\hline 6 & 9 & 2 & 43 & -0.10 & -0.39 & 0.21 & $>0.05$ & $*$ & \\
\hline 10 & 9 & 2 & 96 & -0.07 & -0.27 & 0.13 & $>0.05$ & & \\
\hline 10 & 9 & 4 & 96 & -0.06 & -0.26 & 0.14 & $>0.05$ & $*$ & \\
\hline 6 & 9 & 4 & 43 & 0.14 & -0.17 & 0.42 & $>0.05$ & & \\
\hline 9 & 2 & 5 & 140 & 0.04 & -0.13 & 0.20 & $>0.05$ & $*$ & \\
\hline 1 & 9 & 1 & 89 & 0.09 & -0.12 & 0.29 & $>0.05$ & $*$ & \\
\hline 14 & 9 & 1 & 123 & 0.11 & -0.07 & 0.28 & $>0.05$ & $*$ & \\
\hline All & & & 847 & -0.05 & -0.12 & 0.02 & $>0.05$ & & $<0.05$ \\
\hline Undupl. & & & 708 & -0.05 & -0.12 & 0.02 & $>0.05$ & & $<0.05$ \\
\hline
\end{tabular}

${ }^{1}$ See Index of QOL measures in Figure 1. ${ }^{2}$ Index of impairment measures used in various studies:1 Ventilator dependence; 2 Paraplegia $v s$ tetraplegia; 3 Unspecified 'severity of injury' or 'level of lesion'; 4 Complete $v s$ incomplete injury; 5 ASIA total motor index score 
(Table 4). The apparent lack of homogeneity may be related to the variety of measures of disability that was used in these studies. The average correlation was -0.27 , which is significantly different from 0.00 .
Handicap

The relationship of a large number of aspects of handicap with QOL is reported in this literature, making it possible to analyze the association between

\section{Correlation Coefficient}
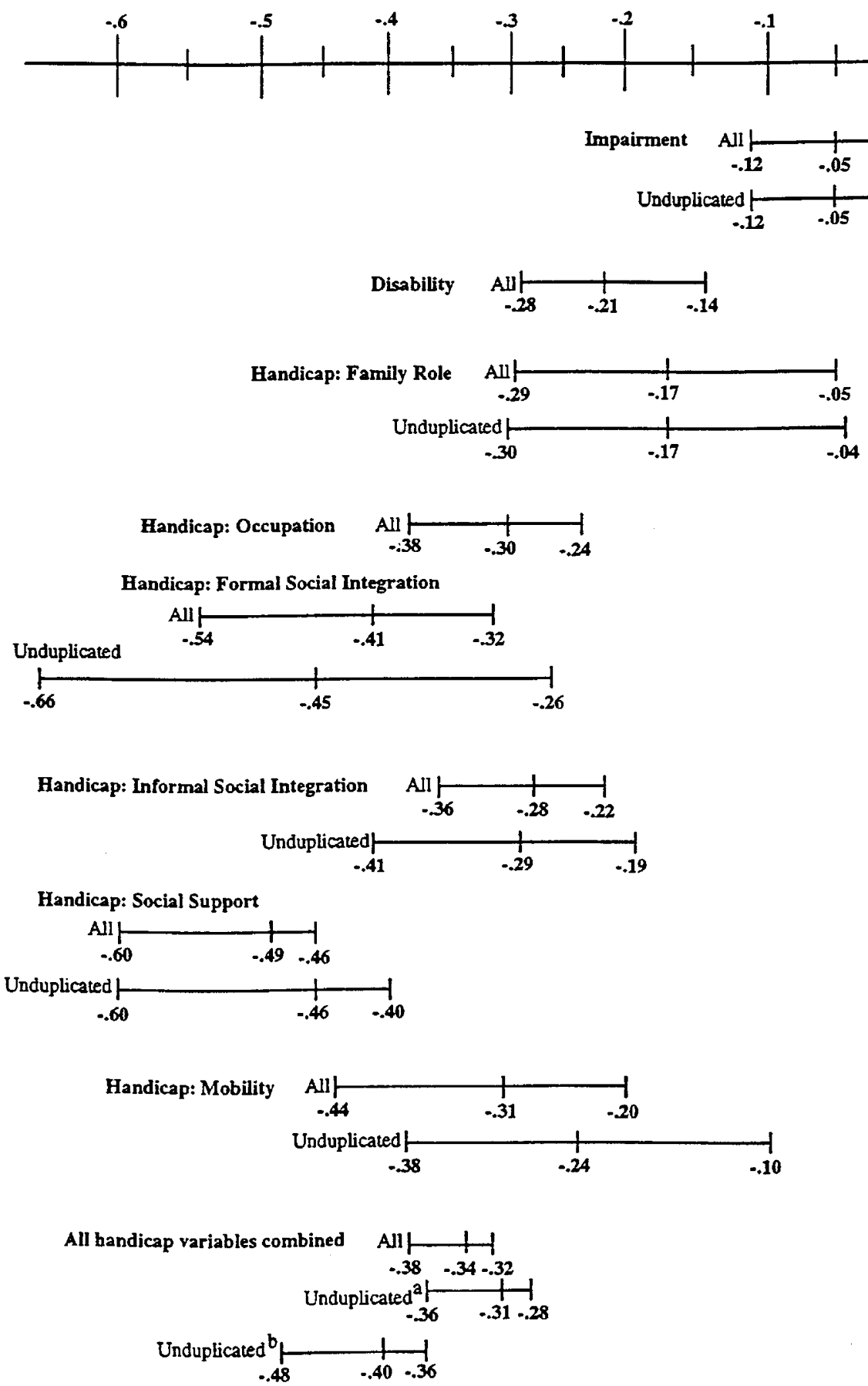

Figure 2 Relationship between QOL and disablement components: correlations and their 95\% confidence interval, based on

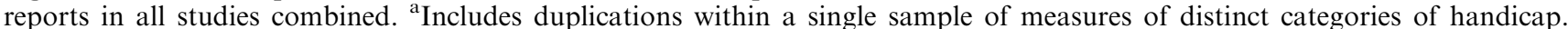

${ }^{\mathrm{b}}$ Includes only one measure of handicap per sample 
Table 4 Results for association of QOL with disability

\begin{tabular}{|c|c|c|c|c|c|c|c|c|c|}
\hline Sample & $\underset{\#^{1}}{Q O L}$ & $\begin{array}{c}\text { Disability } \\
\#^{2}\end{array}$ & Cases & Corr. & $\begin{array}{l}\text { Confidence } \\
\text { Low }\end{array}$ & $\begin{array}{r}\text { Interval } \\
\text { High }\end{array}$ & $\mathrm{p}$ & $\begin{array}{l}\text { Undupl. } \\
\text { sample }\end{array}$ & $\begin{array}{l}\text { Homo- } \\
\text { geneity }\end{array}$ \\
\hline 11 & 5 & 5 & 70 & $?$ & - & - & $>0.05$ & & \\
\hline 8 & 10 & 2 & 31 & -0.66 & -0.82 & -0.39 & $<0.001$ & * & \\
\hline 7 & 2 & 4 & 100 & -0.35 & -0.51 & -0.16 & $<0.001$ & $*$ & \\
\hline 13 & 9 & 4 & 17 & -0.02 & -0.50 & 0.47 & $>0.05$ & $*$ & \\
\hline 4 & 4 & 1 & 91 & -0.24 & -0.42 & -0.04 & $<0.05$ & $*$ & \\
\hline 15 & 9 & 6 & 276 & -0.29 & -0.39 & -0.18 & $<0.05$ & * & \\
\hline 2 & 9 & 3 & 174 & -0.13 & -0.27 & 0.02 & $>0.05$ & $*$ & \\
\hline 9 & 2 & 5 & 140 & 0.07 & -0.10 & 0.23 & $>0.05$ & * & \\
\hline All & & & 829 & -0.21 & -0.27 & -0.14 & $<0.05$ & & $<0.01$ \\
\hline
\end{tabular}

${ }^{1}$ See index of QOL measures in Figure 1. ${ }^{2}$ Index of disability measures used in various studies: 1 Katz ADL scale; 2 Barthel index; 3 FIM motor component; 4 ad-hoc ADL assistance measures; 5 FIM (full); 6 increased need for help

QOL and specific handicap dimensions. Lack of a family role (spousal or parental) seems to result in a lower QOL (Table 5 section $\mathrm{A}$ ); the average correlation is -0.17 . Occupation (work, attending school, or other productive activity) is an even stronger determinant, according to the consensus of ten reports (Table 5 section $\mathrm{B}$ ). The mean correlation is -0.30 ; there is heterogeneity among the reported associations, however, which may be due to both the nature of the samples and the specific occupational activities reported.

Results for the effects of mobility are also provided in Table 5 (section $\mathrm{C}$ ); these suggest that mobility is a fairly strong correlate, with a mean value of -0.31 , indicating that those with a mobility handicap have a lower QOL.

Social integration, into formal social organizations or into networks of friends and acquaintances, is also a fairly strong determinant; however, most correlations reported are from a single study. When duplications are eliminated, a rather strong relationship ( -0.45 for formal; -0.29 for informal) remains (sections D and E).

Social support is yet another aspect of social integration, which reflects the operation of social networks (to the benefit of the respondent), rather than their existence per se. The four samples for which findings are available show a very strong link between QOL and social support, with a mean value of -0.49 ; the test of homogeneity indicates, however, that the sample and/or measure differences produced significantly different results (Table 5 section F).

Two studies reported on aspects of handicap that were not classifiable in the categories listed above; the one paper that reported the size of the correlation found a negative one (section $G$ ).

A comparison of the overall effects of handicap on QOL with those of other characteristics can be based upon the mean correlations reported in Table 6. That there is lack of homogeneity among the correlations considered should not be surprising; if one is willing to disregard such, the correlation between the typical handicap component and QOL can be calculated as
-0.34. Eliminating duplicative items within the categories gives about the same result $(-0.31)$. If duplication from one category to the next is also eliminated, the sample of items drawn happens to show an even higher correlation $(-0.40)$.

\section{Comparison of disablement components}

With the caveats suggested earlier, the mean correlations listed in the above may be compared with one another. In the present case, z-transformed correlations for unduplicated cases were used. The correlation of QOL with handicap $(-0.32)$ is significantly higher (at the $p<0.001$ level) than the correlation of QOL with impairment $(-0.05)$. It similarly is stronger (at $p<0.01)$ than the relationship of disability with QOL $(-0.21)$. The latter in turn is higher $($ at $p<0.01)$ than the correlation between impairment and QOL.

Within the area of handicap, the correlation of social support with QOL is significantly higher (at $p<0.05$ or higher) than the correlation of any other handicap component with QOL. The correlation of formal social integration with QOL $(-0.46)$ is statistically stronger (at $p<0.05)$ than the correlation of the component with the weakest link (family role, with -0.17). All other correlations are not significantly different from one another.

\section{Discussion}

These data indicate that persons with SCI on average report a lower level of subjective well-being than the population at large, or the specific non-disabled comparison groups reported on by the papers identified. The only exceptions are comparisons to populations that may be expected to have a poor subjective well-being - those in jail, or a different disability group, persons with chronic back pain. The comparisons made by the various authors have a number of shortcomings - especially the fact that major determinants of QOL other than health status/ disablement, especially socioeconomic status, gender and age, were not controlled for, statistically or 
Table 5 Results for association of QOL with various components of handicap

\begin{tabular}{|c|c|c|c|c|c|c|c|c|c|}
\hline $\begin{array}{l}\text { Sample } \\
\#\end{array}$ & $\underset{\#^{1}}{Q O L}$ & $\begin{array}{c}\text { Handicap } \\
\#^{2}\end{array}$ & Cases & Corr. & $\begin{array}{l}\text { Confidence } \\
\text { Low }\end{array}$ & $\begin{array}{r}\text { Interval } \\
\text { High }\end{array}$ & $\mathrm{p}$ & $\begin{array}{l}\text { Undupl. } \\
\text { sample }\end{array}$ & $\begin{array}{l}\text { Homo- } \\
\text { geneity }\end{array}$ \\
\hline \multicolumn{10}{|c|}{ A: family role } \\
\hline 6 & 9 & 11 & 43 & $?$ & - & - & $>0.05$ & & \\
\hline 9 & 2 & 11 & 140 & $?$ & - & - & $>0.05$ & & \\
\hline 11 & 5 & 11 & 70 & $?$ & - & - & $>0.05$ & & \\
\hline 16 & 8 & 11 & 85 & neg & - & - & $<0.05$ & & \\
\hline 16 & 8 & 11 & 286 & neg & - & - & $>0.05$ & & \\
\hline 10 & 9 & 12 & 56 & -0.41 & -0.61 & -0.16 & $<0.01$ & * & \\
\hline 13 & 9 & 11 & 17 & -0.17 & -0.60 & 0.34 & $>0.05$ & & \\
\hline 13 & 9 & 11 & 17 & -0.14 & -0.58 & 0.37 & $>0.05$ & $*$ & \\
\hline 2 & 9 & 11 & 174 & -0.09 & -0.24 & 0.06 & $>0.05$ & $*$ & \\
\hline All & & & 264 & -0.17 & -0.28 & -0.05 & $<0.05$ & & $>0.05$ \\
\hline Undupl. & & & 247 & -0.17 & -0.29 & -0.04 & $<0.05$ & & $>0.05$ \\
\hline \multicolumn{10}{|c|}{ B: occupation } \\
\hline 4 & 4 & 32 & 91 & $?$ & - & - & $>0.05$ & & \\
\hline 6 & 9 & 32 & 43 & neg & - & - & $>0.05$ & & \\
\hline 10 & 9 & 32 & 98 & neg & - & - & $<0.001$ & & \\
\hline 13 & 9 & 35 & 17 & -0.21 & -0.63 & 0.30 & $>0.05$ & $*$ & \\
\hline 5 & 2 & 32 & 60 & -0.39 & -0.59 & -0.15 & $<0.01$ & $*$ & \\
\hline 16 & 8 & 32 & 232 & -0.46 & -0.56 & -0.35 & $<0.01$ & $*$ & \\
\hline 10 & 9 & 35 & 50 & -0.31 & -0.54 & -0.03 & $<0.05$ & $*$ & \\
\hline 7 & 2 & 32 & 100 & -0.33 & -0.49 & -0.14 & $<0.001$ & $*$ & \\
\hline 11 & 5 & 32 & 70 & -0.29 & -0.49 & -0.06 & $<0.05$ & $*$ & \\
\hline 19 & 2 & 24 & 140 & -0.24 & -0.39 & -0.07 & $<0.01$ & $*$ & \\
\hline 2 & 9 & 31 & 174 & -0.09 & -0.24 & 0.06 & $>0.05$ & $*$ & \\
\hline All & & & 843 & -0.30 & -0.36 & -0.24 & $<0.05$ & & $<0.05$ \\
\hline \multicolumn{10}{|c|}{ C: mobility } \\
\hline 6 & 9 & 71 & 43 & $?$ & - & - & $>0.05$ & & \\
\hline 10 & 9 & 73 & 56 & -0.53 & -0.70 & -0.31 & $<0.01$ & & \\
\hline 10 & 9 & 74 & 56 & -0.32 & -0.54 & -0.06 & $<0.05$ & $*$ & \\
\hline 9 & 2 & 72 & 140 & -0.21 & -0.36 & -0.04 & $<0.05$ & $*$ & \\
\hline All & & & 252 & -0.31 & -0.42 & -0.19 & $<0.05$ & & $>0.05$ \\
\hline Undupl. & & & 196 & -0.24 & -0.36 & -0.10 & $<0.05$ & & $>0.05$ \\
\hline \multicolumn{10}{|c|}{ D: formal social integration } \\
\hline 3 & 1 & 43 & 100 & -0.49 & -0.63 & -0.32 & $<0.05$ & & \\
\hline 3 & 1 & 41 & 100 & -0.45 & -0.59 & -0.28 & $<0.05$ & $*$ & \\
\hline 3 & 1 & 42 & 100 & -0.25 & -0.43 & -0.06 & $>0.05$ & & \\
\hline All & & & 300 & -0.41 & -0.50 & -0.31 & $<0.05$ & & $>0.05$ \\
\hline Undupl. & & & 100 & -0.45 & -0.59 & -0.28 & $<0.05$ & & - \\
\hline \multicolumn{10}{|c|}{ E: informal social integration } \\
\hline 10 & 9 & 57 & 56 & -0.39 & -0.59 & -0.14 & $<0.01$ & $*$ & \\
\hline 3 & 1 & 53 & 100 & -0.40 & -0.55 & -0.22 & $<0.05$ & & \\
\hline 3 & 1 & 54 & 100 & -0.34 & -0.50 & -0.15 & $<0.05$ & & \\
\hline 3 & 1 & 51 & 100 & -0.27 & -0.44 & -0.08 & $>0.05$ & $*$ & \\
\hline 3 & 1 & 55 & 100 & -0.27 & -0.44 & -0.08 & $>0.05$ & & \\
\hline 9 & 2 & 56 & 140 & -0.26 & -0.41 & -0.10 & $<0.01$ & $*$ & \\
\hline 3 & 1 & 52 & 100 & -0.09 & -0.28 & 0.11 & $>0.05$ & & \\
\hline & & & 696 & -0.28 & -0.35 & -0.21 & $<0.01$ & & $>0.05$ \\
\hline Undupl. & & & 296 & -0.29 & -0.39 & -0.18 & $<0.05$ & & $>0.05$ \\
\hline
\end{tabular}


Table 5 (continued)

\begin{tabular}{|c|c|c|c|c|c|c|c|c|c|}
\hline $\begin{array}{l}\text { Sample } \\
\#\end{array}$ & $\underset{\#^{1}}{Q O L}$ & $\begin{array}{c}\text { Handicap } \\
\#^{2}\end{array}$ & Cases & Corr. & $\begin{array}{l}\text { Confidence } \\
\text { Low }\end{array}$ & $\begin{array}{r}\text { Interval } \\
\text { High }\end{array}$ & $\mathrm{p}$ & $\begin{array}{l}\text { Undupl. } \\
\text { sample }\end{array}$ & $\begin{array}{l}\text { Homo- } \\
\text { geneity }\end{array}$ \\
\hline \multicolumn{10}{|c|}{ F: social support } \\
\hline 11 & 5 & 64 & 70 & -0.75 & -0.84 & -0.63 & $<0.01$ & & \\
\hline 11 & 5 & 62 & 70 & -0.72 & -0.82 & -0.58 & $<0.01$ & $*$ & \\
\hline 11 & 5 & 63 & 70 & -0.66 & -0.77 & -0.50 & $<0.01$ & & \\
\hline 7 & 2 & 61 & 100 & -0.45 & -0.59 & -0.28 & $<0.001$ & $*$ & \\
\hline 5 & 2 & 61 & 60 & -0.39 & -0.59 & -0.15 & $<0.01$ & $*$ & \\
\hline 7 & 7 & 61 & 100 & -0.42 & -0.57 & -0.24 & $<0.001$ & & \\
\hline 9 & 2 & 65 & 140 & -0.33 & -0.47 & -0.17 & $<0.01$ & $*$ & \\
\hline 9 & 2 & 61 & 140 & -0.32 & -0.46 & -0.16 & $<0.01$ & & \\
\hline All & & & 750 & -0.49 & -0.54 & -0.43 & $<0.01$ & & $<0.001$ \\
\hline Undupl. & & & 370 & -0.46 & -0.54 & -0.38 & $<0.05$ & & $<0.001$ \\
\hline \multicolumn{10}{|c|}{ G: other aspects of handicap } \\
\hline 6 & 9 & 91 & 43 & $?$ & - & - & $>0.05$ & & \\
\hline 2 & 9 & 92 & 174 & -0.18 & -0.32 & -0.03 & $<0.05$ & & \\
\hline All & & & 174 & -0.18 & -0.32 & -0.03 & $<0.05$ & & - \\
\hline
\end{tabular}

${ }^{1}$ See index of QOL measures in Figure 1. ${ }^{2}$ Index of handicap measures used in various studies: 11 marital status; 12 home making; 13 parenting; 31 student status; 32 employment status; 33 yes/no employment income; 34 CHART occupation; 35 work/study status; 41 activity in social organizations; 42 frequency of attendance church services; 43 voluntary organization memberships; 51 frequency visiting neighbors; 52 number of close friends; 53 frequency of interacting with friends/relatives; 54 in-home visits by friends; 55 out-of-home visits friends; 56 CHART social integration; 57 social activity level; 61 Decker/Schulz measure; 62 ISEL-instrumental; 63 ISEL-information; 64 ISEL-emotional; 71 driving; 72 CHART mobility; 73 owning a car; 74 neighborhood mobility; 91 regular exercise; 92 frequency out exercising

Table 6 Results for association of QOL with all handicap variables combined

\begin{tabular}{lcccccc}
\hline $\begin{array}{l}\text { Sample } \\
\#\end{array}$ & Cases & Corr. & Low & High & p & Homo- \\
geneity
\end{tabular}

${ }^{1}$ Includes duplications from studies listing handicap measures for two or more categories of handicap. ${ }^{2}$ Includes only one measure of handicap per sample

otherwise. However, the consistency of the result is quite convincing: the average person with a spinal injury experiences a lower quality of life than the average person without such injury.

Components of disablement are likely explanations for this discrepancy. The World Health Organization's distinction of three separate, but causally and temporally related constructs is a useful conceptualization to 'tease apart' the train of consequences of disease and injury. ${ }^{57}$ Spinal cord injury is an 'ideal type' (in the Weberian meaning of the term) for the study of disablement, for several reasons. The most important is that the three components can be measured separately, with a high level of sensitivity. In addition, cognitive deficits, which generally cannot so neatly be split into impairments and disabilities, ${ }^{58}$ in most patients with SCI are absent or of minor import. Lastly, SCI typically is incurred by young people who are basically healthy; deficits due to other disorders or to aging are not there to cloud the picture. While the specific findings from the current meta-analysis may not be generalizeble to other disability groups, the overall outline of the linkages between disablement components and subjective wellbeing should apply broadly.

It would appear that Fuhrer $^{32}$ was right in concluding, based upon his qualitative summary of the literature, that QOL appears to be little, if at all, related to impairment, and commonly to various aspects of handicap. His characterization of the relationship between QOL and disability as inconsistent would seem less appropriate: six out of seven correlations identified were negative with a range from -0.02 (for a small study with $N$ of 17 ), to -0.66 (from a report that may be marred by typographical or statistical problems).

While it is tempting to think of the relationship between QOL and the various disablement components as one of simple one-way causation (that is: disablement is the cause of quality of life), that is not 
necessarily correct, and reciprocal causation should be seen as a possibility. It is conceivable for quality of life to affect impairment, especially if secondary disablement resulting from lifestyle issues etc. are considered. Even more likely, subjective well-being may affect disability and handicap. Someone who for whatever reason does feel that his or her life is not the best it could be is not likely to engage in self care activities that constitute an effort, let alone spend energy in taking up or discharging the various social roles that are wrapped up in handicaps. Without longitudinal designs that make it possible to statistically separate out the effects of QOL on eg handicap and vice versa, it is difficult to estimate to what degree subjective wellbeing affects handicap and disability.

This meta analysis did not correct effect sizes for various methodological shortcomings of the studies summarized, as is practiced by the adherents of the approach of Hunter and Schmidt. ${ }^{59}$ Specifically, many of the studies used single-item measures of QOL, which have low reliability. This attenuates the correlation between QOL and its predictor variables. Similarly, no correction was made for dichotomization of continuous variables, eg impairment, which generally was reported as a paraplegia versus tetraplegia or other two-group distinction. Handicaps also were often measured as simple dichotomies (yes/ no married, for instance), although more sensitive measures were not uncommon.

On the other hand, the association between QOL and its best predictors among the handicap factors may have been artificially inflated. As is the case in almost all studies of social support, social support was never measured independently from the recipient, the person with SCI. Because generally the subjects in these studies completed social support measures at the same time that they completed subjective well-being measures, contamination may have occurred. Some subjective well-being indices even include support items, indicating how closely related the two are. For that reason, one may want to exclude the concept of social support from the factors constituting handicap. Even if there is no need for such, and there is no overlap between QOL measure and social support measure, tainting of the association is a possibility. Quality of life indices, both life satisfaction and happiness ones, would seem to be subject to social desirability problems, although Diener et $a l^{60}$ reported there was no such problem with the Satisfaction with Life Scale.

An earlier meta-analysis of the relationship between disablement and QOL in spinal cord injury by Evans et $a l^{61}$ also came to the conclusion that among persons with SCI, QOL is negatively correlated $(-0.22)$ with disability. However, as was pointed out by Fuhrer, ${ }^{32}$ that analysis used both 'objective' and 'subjective' QOL measures interchangeably, and did not distinguish between impairment, disability and handicap.

Evans and associates ${ }^{61}$ did, however, address the 'file drawer problem' - the concern that because of the bias of researchers, peer reviewers and editors, positive (that is, statistically significant) results get into the published literature, while negative ones (no rejection of the null hypothesis) never get written up, or at least never get further than the file drawer or an editor's desk. Evans et al performed a test to determine to what degree the result of their analysis was 'at risk' for the same reason, and found that 22 studies confirming the null hypothesis (of no relationship) would need to exist to offset their result - an unlikely state of affairs. Most of the studies included in the present analysis did not have a specific hypothesis to begin with, but aimed to describe an SCI sample, using a variety of socio-psychological and other outcome measures, including an index or item of QOL. The authors avoided a file drawer destination by reporting selected findings of interest. 'Negative' results were frequently reported (see the Tables), although generally not with as much specificity as is needed for meta analysis: in case of the 'not significant' test result, the specific parameters were not supplied. However, given this pattern, and Evans et al's earlier finding, ${ }^{6}$ it is not expected that unpublished research exists to contradict the current findings.

At several points it was noted that the effect sizes reported were heterogeneous. Analysis of those characteristics of the samples (average age, percent female, etc.) or the variables (specific QOL measure used, disablement measure used, etc) distinguishing low from high effect sizes is a possible solution to such a problem; the samples (effect sizes) are split into smaller, more homogeneous groups which are used to test ad-hoc hypotheses (eg 'single item QOL measures will result in weaker correlations due to more extensive attenuation'). However, the number of studies currently available is too small, and the $N$ of cases for each too limited, to make possible analysis of factors that explain contradictory findings, beyond weak ad-hoc guesses based on the data. Presumably, with the focus on QOL currently found in the medical and rehabilitation literature, in 5 or 10 years there may be more studies, reported in adequate detail, and such an analysis will be possible.

Because subjective quality of life is such a new area of study, the literature is lacking in hypotheses as to what specific elements of the "cascade of consequences of injury' ${ }^{3}$ have the most effect on well-being. The findings reported here may come as a surprise to some - for instance, that body integrity issues play no large role. To others, they may constitute a confirmation - eg that integration into family, the world of work and the larger community is the most crucial element. In a sense, the ranking of the three disablement constructs in terms of their correlation with QOL is good news: while there currently is little that can be done to decrease impairment (especially in chronic SCI patients), rehabilitation specialists have the skills to diminish disability (using training, providing aids and appliances, etc). They also can do 
much to minimize handicap, although changes in the larger society often are also needed, eg breaking down of attitudinal barriers.

Further research in this area is needed, in order to investigate the relationship of subjective well-being to disablement in more detail. Specifically needed is longitudinal research utilizing clinicometrically strong measures of impairment (eg ASIA motor scale ${ }^{56}$ ), disability (eg FIM ${ }^{62}$ ), and (elements of) handicap (eg $\mathrm{CHART}^{63}$ ) in one and the same study, along with valid and reliable measures of (various aspect of) subjective well-being.

Knowledge as to what factors contribute most to subjective QOL after SCI may assist policy makers in deciding which interventions to support in order to maximize QOL generated per dollar invested. The measurement of QOL may contribute to a very realistic and pragmatic evaluation of the outcomes of policies, programs and interventions. Similarly, knowledge of QOL and its determinants may assist service providers to be more aware of interindividual variations, and of the effect of social variables (race, ethnic group, generation) on this patterning. Only the perspective of patients/clients themselves is a useful guide to where resources can be utilized most effectively.

\section{Acknowledgements}

Thanks to Colette Hillebrand Duggan Ph.D. for painstakingly abstracting the papers included in the meta analysis. Preparation of this manuscript was made possible in part with financial assistance from the National Institute on Disability and Rehabilitation Research (grants H133N50006 and H133G50138).

\section{References}

1 Brown MJ, Gordon WA, Ragnarsson K. Unhandicapping the disabled: What is possible? Arch Phys Med Rehabil 1987; 68: $206-209$.

2 Tate DG, Dijkers M, Johnson-Greene L. Outcome measures in quality of life. Top Stroke Rehabil 1996; 2: 1-17.

3 Dijkers M. Measuring quality of life. In: Fuhrer M (ed) Assessing medical rehabilitation practices: the promise of outcomes research. Baltimore: Brookes Publishing Co, 1977, pp 153-179.

4 Andrews F, Withey S. Social indicators of well-being: Americans perceptions of life quality. New York: Plenum Press, 1976.

5 Campbell A, Converse P, Rodgers W. The quality of American life. New York: Sage, 1976.

6 Cantril H. The pattern of human concerns. New Brunswick, NY: Rutgers University Press, 1965.

7 Zhan L. Quality of life: conceptual and measurement issues. $J$ Advanced Nursing 1992: 17: 795-800.

8 Bradburn N. The structure of psychological well-being. Chicago: Aldine, 1969.

9 Whiteneck G et al. Mortality, morbidity and psychological outcomes of persons spinal cord injured more than 20 years ago. Paraplegia 1992; 30: 617-630.

10 Dijkers MP, Buda Abela M, Gans BM, Gordon WA. The aftermath of spinal cord injury. In: Stover SL, DeLisa JA, Whiteneck GG. (eds) Spinal cord injury: Clinical outcomes from the model systems. Rockville: Aspen, 1995, pp 185-212.
11 DeVivo M, Richards JS. Community reintegration and quality of life following spinal cord injury. Paraplegia 1992; 30: $108-112$.

12 Quiel V. Fragen zur Lebensqualität nach Querschnittlähmung - Erfahrungen bei der gynaekologischen Betreuung von Paraplegikerinnen. Rehabilitation 1994; 33: 44 - 46.

13 Tate DG, Maynard F, Forchheimer M. Predictors of psychologic distress one year after spinal cord injury. Am J Phys Med Rehabil 1993; 72: $272-275$.

14 Crewe NM, Krause JS. Marital status and adjustment to spinal cord injury. J Am Paraplegia Soc 1992; 15: 14-18.

15 Hanson S, Buckelew S, Hewett J, O'Neal G. The relationship between coping and adjustment after spinal cord injury: a 5-year follow-up study. Rehabil Psychol 1993; 38: 41 - 52.

16 MacDonald M, Nelsen W, Cameron M. Depression and activity patterns of spinal cord injured persons living in the community. Arch Phys Med Rehabil 1987; 68: 339-343.

17 Richards JS. Psychologic adjustment to spinal cord injury during first post discharge year. Arch Phys Med Rehabil 1986; 67: $362-$ 365.

18 Schultz R, Decker S. Long-term adjustment to physical disability: The role of social support, perceived control and self-blame. J Pers Soc Psychol 1985; 48: $1162-1172$.

19 Rintala DH et al. Social support and the well-being of persons with spinal cord injury living in the community. Rehabil Psychol 1992; 37: $155-163$.

20 Crewe N. Quality of life: The ultimate goal in rehabilitation. Minn Med 1980; 163: 586-589

21 Flanagan J. A research approach to improving our quality of life. Am Psychol 1978; 13: $138-147$.

22 Decker S, Schultz R. Correlates of life satisfaction and depression in middle-aged and elderly spinal-cord injured persons. Am J Occup Ther 1985; 39: 740-745.

23 Lundqvist $\mathrm{C}$ et al. Spinal cord injuries. Clinical, functional and emotional status. Spine 1991; 16: $78-83$.

24 Boschen KA. Life satisfaction, housing satisfaction and locus of control: a comparison between spinal cord injured and nondisabled individuals. Can J Rehabil 1990; 4: 75-88.

25 Dew M, Lynch K, Ernst J, Rosenthal R. Reaction and adjustment to spinal cord injury: a descriptive study. $J \mathrm{Appl}$ Rehabil Counseling 1983; 14: $32-39$.

26 Crisp R. Long-term adjustment of 60 persons with spinal cord injury. Aust Psychol 1992; 27: 43 - 47.

27 Fuhrer $\mathrm{M}$ et al. Relationship of life satisfaction to impairment, disability and handicap among persons with spinal cord injury living in the community. Arch Phys Med Rehabil 1992; 73: 552557.

28 Eisenberg M, Saltz C. Quality of life among aging spinal cord injured persons: long term rehabilitation outcomes. Paraplegia 1991; 29: $514-520$.

29 Paralyzed Veterans of America. Final Report: PVA needs assessment survey. Washington DC: author, 1988.

30 Dunnum L. Life satisfaction and spinal cord injury: the patient perspective. J Neurosci Nurs 1990; 22: $43-47$.

31 Krause JS. Life satisfaction after spinal cord injury: a descriptive study. Rehabil Psychol 1992; 37: 61-70.

32 Fuhrer MJ. The subjective well-being of people with spinal cord injury: relationships to impairment, disability and handicap. Topics Spinal Cord Inj Rehabil 1996; 1: 56-71.

33 Siösteen A et al. Sexual ability, activity, attitudes and satisfaction as part of adjustment in spinal cord injured subjects. Paraplegia 1990; 28: $285-295$.

34 Stensman R. Severely mobility-disabled people assess the quality of their lives. Scan J Rehabil Med 1985; 17: 87-99.

35 Chwalisz K, Diener E, Gallagher D. Autonomic arousal feedback and emotional experience: evidence from the spinal cord injured. J Pers Soc Psychol 1988; 54: 820-828.

36 Bach JR, Tilton MC. Life satisfaction and well-being in ventilator assisted individuals with traumatic tetraplegia. Arch Phys Med Rehabil 1994; 75: 626-632.

37 Buda Abela M, Dijkers M. Predicting life satisfaction among spinal cord injured patients one to three years post-injury. Poster presentation at the Annual Meetings of the American Spinal Injury Association, Philadelphia PA, 1994. 
38 Clayton KS, Chubon RA. Factors associated with the quality of life of long-term spinal cord injured persons. Arch Phys Med Rehabil 1994; 75; 633-638.

39 Coyle CP, Lesnik-Emas S, Kinney WB. Predicting life satisfaction among adults with spinal cord injuries. Rehabil Psychol 1994; 39: 95-112.

40 Cushman LA, Hassett J. Spinal cord injury: 10 and 15 years after. Paraplegia 1992; 30: 690-696.

41 Siösteen A et al. The quality of life of three functional spinal cord injury subgroups in a Swedish community. Paraplegia 1990; 28: $476-485$.

42 McColl MA, Rosenthal C. A model of resource needs of aging spinal cord injured men. Paraplegia 1994; 32: $261-270$.

43 Nieves C, Charter R, Aspinall MJ. Relationship between effective coping and perceived quality of life in spinal cord injured patients. Rehabil Nurs 1991; 16: 129-132.

44 Stensman R. Adjustment to traumatic spinal cord injury: longitudinal study of self-reported quality of life. Paraplegia 1994; 32: $416-422$

45 Whiteneck GG et al. A collaborative study of high quadriplegia. Englewood, Colorado: Craig Hospital, 1985.

46 Gerhart KA et al. Long-term spinal cord injury: functional changes over time. Arch Phys Med Rehabil 1993; 74: 1030 - 1034

47 Krause JS. Longitudinal changes in adjustment after spinal cord injury: a 15 year study. Arch Phys Med Rehabil 1992; 73: 564 568.

48 Krause JS. Adjustment to life after spinal cord injury: a comparison among three participant groups based on employment status. Rehabil Counseling Bull 1992; 35: 218 - 229.

49 Krause JS, Kjorsvig JM. Mortality after spinal cord injury: a four-year prospective study. Arch Phys Med Rehabil 1992; 73: $558-563$.

50 Krause JS, Dawis RV. Prediction of life satisfaction after spinal cord injury: a four-year longitudinal approach. Rehabil Psychol 1992; 37: 49-59.

51 Krause JS, Crewe NM. Prediction of long-term survival of persons with spinal cord injury: an 11-year prospective study. Rehabil Psychol 1987; 32: 205-213.
52 Krause JS, Crewe NM. Chronologic age, time since injury, and time of measurement: effect on adjustment after spinal cord injury. Arch Phys Med Rehabil 1991; 72: $91-100$.

53 Brickman P, Coates D, Janoff-Bulman R. Lottery winners and accident victims: is happiness relative? J Personality Soc Psychol 1978; 6: $917-927$.

54 Yerxa EJ, Baum S. Engagement in daily occupations and life satisfaction among people with spinal cord injuries. Occup Therap J Research 1986; 6: 271 - 283.

55 Rosenthal R. Meta-analytic procedures for social research (Revised edition). Newbury Park, CA: Sage, 1991.

56 American Spinal Injury Association. Standards for neurological and functional classification of spinal cord injury (Revised 1992). Chicago; Author, 1992.

57 World Health Organization. International classification of impairments, disabilities and handicaps. A manual of classification relating to the consequences of disease. Geneva: Author. 1980; reprinted 1993.

58 Wiersma D. Psychological impairments and social disabilities: on the applicability of the ICIDH to psychiatry. Intern Rehabil Med 1986; 8: $3-7$

59 Hunter JE, Schmidt FL. Methods of meta-analysis: correcting error and bias in research findings. Newbury Park, CA: Sage, 1990.

60 Diener E, Emmons R, Larsen R, Griffin S. The satisfaction with life scale. J Pers Assess 1985; 49: 71 - 75 .

61 Evans RL et al. Quality of life after spinal cord injury: a literature critique and meta-analysis (1983-1992). J Am Paraplegia Soc 1994; 17: $60-66$

62 Hamilton B, Granger C, Sherwin F. A uniform national data system for medical rehabilitation. In: Fuhrer M. (ed) Rehabilitation outcomes: analysis and measurement. Brookes, Baltimore, 1987, pp $137-147$

63 Whiteneck $\mathrm{G}$ et al. Quantifying Handicap: A new measure of long-term rehabilitation outcomes. Arch Phys Med Rehabil 1992; 73: $519-526$ 